\title{
Nebulization During Spontaneous Breathing, CPAP, and Bi-Level Positive-Pressure Ventilation: A Randomized Analysis of Pulmonary Radioaerosol Deposition
}

\author{
Juçara Gasparetto Maccari MD, Cassiano Teixeira MD PhD, \\ Augusto Savi PT PhD, Roselaine Pinheiro de Oliveira MD PhD, \\ André Sant'Ana Machado MD, Tulio Frederico Tonietto MD, Eduardo Ludwig, \\ Paulo José Zimermann Teixeira MD PhD, and Marli Maria Knorst MD PhD
}

\begin{abstract}
BACKGROUND: There have been few reports of factors affecting aerosol delivery during noninvasive ventilation (NIV). Nebulization is a standard practice, and our objective was to determine the effect of spontaneous breathing (SB) and NIV mode on lung technetium-99m $\left({ }^{99 m} \mathrm{Tc}\right)$ deposition in subjects with normal lungs. METHODS: Thirteen health care volunteers were submitted to a randomized radioaerosol nebulization with ${ }^{99} \mathrm{~m}_{\mathrm{Tc}}$ during $\mathrm{SB}$, CPAP $\left(10 \mathrm{~cm} \mathrm{H}_{2} \mathrm{O}\right)$, and bi-level positive-pressure ventilation (bi-level; inspiratory-expiratory pressures of $15 / 5 \mathrm{~cm}_{2} \mathrm{O}$ ). NIV was performed via a ventilator (VPAP II ST-A, ResMed, Sydney, Australia). The radioaerosol deposition was evaluated by pulmonary scintigraphy after $10 \mathrm{~min}$ of inhalation. Regions of interest (ROIs) were outlined on the left lung (LL), right lung (RL), and trachea (TRQ). The average number of counts/pixel in each ROI was determined, and the ratio of lung and trachea was calculated. RESULTS: The three techniques showed comparable lung deposition. Analysis of radioaerosol deposition in the lungs showed a mean count at RL of $108.7 \pm 40$ with CPAP, $111.5 \pm 15$ with bi-level, and 196.6 \pm 167 with SB. At $L L$, the values were $92.7 \pm 15$ with CPAP, $98.4 \pm 14$ with bi-level, and $225.0 \pm 293$ with SB. There was no difference between the means of radioaerosol deposition in RL, $L L$, or TRQ, as well as the lung calculated ratio (LCR $=[R L+L L] / T R Q)$, which was similar in comparing ventilatory strategies. CONCLUSIONS: Based on our data, there is an equivalent deposition of inhaled substances in individuals with healthy lungs when SB, CPAP, and bi-level are compared. Key words: nebulization during spontaneous breathing; noninvasive ventilation; aerosol therapy; radioaerosol deposition. [Respir Care 2014;59(4):479-484. (C) 2014 Daedalus Enterprises]
\end{abstract}

\section{Introduction}

Many patients suffering from acute respiratory failure due to exacerbation of COPD require some form of ven-

Drs Maccari, Zimermann Teixeira, and Knorst are affiliated with the Graduate Program in Pneumology, Department of Pulmonary Medicine, Federal University of Rio Grande do Sul School of Medicine, Porto Alegre, Brazil. Drs Maccari, Teixeira, Pinheiro de Oliveira, Savi, Sant'Ana Machado, and Tonietto are affiliated with the Department of Intensive Care, and Dr Ludwig is affiliated with the Department of Nuclear Medicine, Moinhos de Vento Hospital, Porto Alegre, Brazil. Drs Teixeira and Pinheiro de Oliveira are also affiliated with the Federal University of Health Sciences School of Medicine, Porto Alegre, Brazil.

The authors have disclosed no conflicts of interest. tilatory support. ${ }^{1,2}$ The ventilatory strategy employed in such patients has evolved over the past few years, and noninvasive ventilation (NIV) is now considered a firstline modality of ventilatory support for patients with exacerbations of COPD. ${ }^{2-6}$ NIV has been successfully used to improve gas exchange and to avoid intubation..$^{2,3,6} \mathrm{NIV}$ also reduces the work of breathing and averts the circle leading to acute respiratory failure by counterbalancing

Correspondence: Juçara Gasparetto Maccari MD, Ramiro Barcelos, 910/ CTI-Adulto, Porto Alegre, RS 90035-001, Brazil. E-mail: ju.maccari@ hotmail.com.

DOI: $10.4187 /$ respcare. 02518 
intrinsic PEEP with extrinsic PEEP, by unloading respiratory muscles, and by augmenting tidal volume. ${ }^{5}$

Despite the number of therapies used to treat respiratory diseases, inhalation therapy in clinical practice is usually via metered-dose inhaler (MDI), powder inhaler, or nebulizers. ${ }^{7}$ COPD patients receiving NIV also require inhaled bronchodilators for relief of airway obstruction. ${ }^{5,8}$ Nebulization associated with NIV is used in emergency services and ICUs, not only as a form of reverting bronchial obstruction but also of reducing work of breathing; in fact, the efficiency of a nebulized drug during nebulization via NIV depends on the effectiveness of the drug deposition in the lungs. ${ }^{8} 9$ The deposition of an aerosol in the lung may vary widely according to many parameters, including the type of nebulizer and the type of compressor used to produce the aerosol, the nebulizer fill, the injected flow, and the breathing pattern. ${ }^{9,10}$ Unfortunately, there is a paucity of information regarding the use of aerosol therapy in patients receiving NIV, and a better understanding of the factors influencing aerosol drug delivery during this mode of ventilation is needed for the development of guidelines. ${ }^{7-14}$ Thus, heterogeneous drug deposition has been demonstrated in vitro ${ }^{9,12,14,15}$ and in vivo, such as in healthy individuals ${ }^{11,16}$ and in patients with cystic fibrosis, ${ }^{17}$ asthma, ${ }^{8,18,19}$ and COPD. ${ }^{13,20}$

Scintigraphy has been used to analyze peripheral deposition of aerosol during NIV compared with spontaneous breathing (SB). ${ }^{19}$ Previous studies have compared bi-level positive-pressure ventilation (bi-level) with $\mathrm{SB}^{7,11,19,20}$ and CPAP with SB, ${ }^{12}$ but comparison of the three methods has not been carried out until now. Therefore, the objective of this study was to analyze the pulmonary regional deposition of radioaerosol administered by nebulization to healthy individuals during SB and during two modes of NIV (CPAP and bi-level).

\section{Methods}

\section{Subjects}

Thirteen healthy volunteers ( 10 men and 3 women) were studied. Their mean age was $30.8 \pm 4 \mathrm{y}$, and their body mass index (BMI) was $23.3 \pm 2.9 \mathrm{~kg} / \mathrm{m}^{2}$. Exclusion criteria were: $<18$ or $>60$ y of age, history of smoking or respiratory diseases (COPD, asthma, or tuberculosis), cardiac disease, pregnancy, conditions requiring systemic corticosteroids, $\mathrm{FEV}_{1}<2 \mathrm{~L}$, peak expiratory flow $<300 \mathrm{~L} /$ $\min , \mathrm{BMI}>30 \mathrm{~kg} / \mathrm{m}^{2}$, neuromuscular disease diagnosis, or maximum inspiratory pressure $>-30 \mathrm{~cm} \mathrm{H}_{2} \mathrm{O}$.

\section{Measurements and Procedures}

Volunteers were asked about their age, history of smoking, and any previous pulmonary illness. Anthropometric

\section{QUICK LOOK}

\section{Current knowledge}

Noninvasive ventilation and aerosolized bronchodilator therapy are mainstays in the early treatment of COPD exacerbation. The unique aspects of ventilation via face mask add complexity to aerosol delivery to the respiratory tract.

\section{What this paper contributes to our knowledge}

In a group of normal volunteers, there was no difference in deposition of radiolabeled aerosol via updraft nebulizer during spontaneous breathing, continuous positive airway pressure, or bi-level ventilation.

data (weight, height, and BMI) were collected, and cardiopulmonary assessment was then carried out. Maximum inspiratory pressure was obtained using a manometer (Famabras, São Paulo, Brazil); FVC and FEV 1 were measured using a spirometer (Satellite subminiature, Jones Spirometer, Windsor, United Kingdom).

All volunteers were randomly submitted (at least 1 week apart) to bi-level (inspiratory-expiratory pressures of 15/ $\left.5 \mathrm{~cm} \mathrm{H}_{2} \mathrm{O}\right)$, CPAP $\left(10 \mathrm{~cm} \mathrm{H}_{2} \mathrm{O}\right)$, and SB. NIV was performed via a ventilator (VPAP II ST-A, ResMed, Sydney, Australia). In both phases, the radioaerosol used was technetium-99m $\left({ }^{99 \mathrm{~m}} \mathrm{Tc}\right)$, which was generated via a jet nebulizer (Micro-Nebulizer NS, NS Medical Devices, São Paulo, Brazil), diluted in $0.9 \%$ saline solution to a volume of $3 \mathrm{~mL}$, and placed in a leaded box. Aerosol flow was set at $7 \mathrm{~L} / \mathrm{min}$ via an oxygen tank. The tests were all performed in the Department of Nuclear Medicine at the Moinhos de Vento Hospital (Porto Alegre, Brazil). Radioaerosol inhalation was carried out via a face mask (anesthesia air cushion mask) attached by straps to a volunteer's head, who was seated. All volunteers were trained previously for mask adaptation and breathing pattern. The circuit is shown schematically in Figure 1.

The deposition of ${ }^{99 \mathrm{~m}} \mathrm{Tc}$ was evaluated by pulmonary scintigraphy after $10 \mathrm{~min}$ of inhalation. Regions of interest (ROIs) were outlined on the left lung (LL), right lung (RL), trachea (TRQ), mouth, and stomach. The average number of counts/pixel in each ROI was determined, and the ratio of RL, LL, and TRQ was calculated by: lung calculated ratio $(\mathrm{LCR})=(\mathrm{RL}+\mathrm{LL}) / \mathrm{TRQ}$. The ratio of lung deposition (LL and RL) and the number of counts/ pixel in the mouth, stomach, and all sites (TRQ, mouth, and stomach) were also calculated.

The study protocol was approved by the institutional ethics committee of Moinhos de Vento Hospital. All volunteers gave informed consent. 


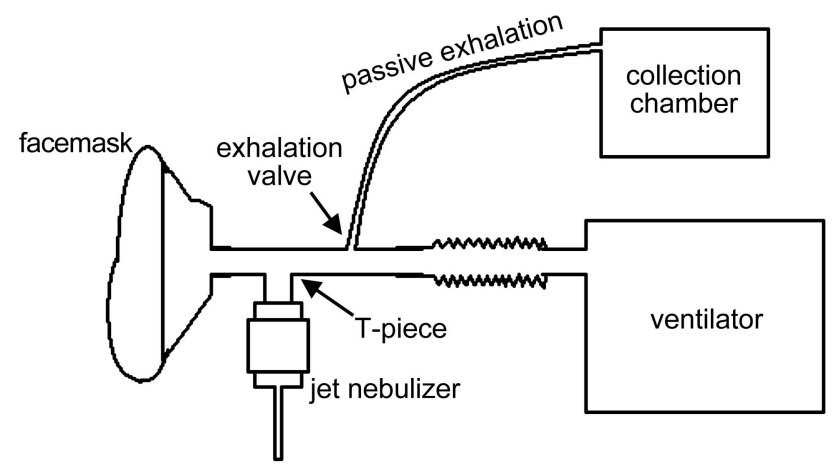

Fig. 1. Circuit schematic.

\section{Statistical Analysis}

Data are presented as mean \pm SD or median (minimum-maximum). Lung deposition was analyzed using the Friedman test (repeated measures), with a level of significance of $P<.05$ for the comparisons of scintigraphic parameters. We used the Wilcoxon rank-sum test to compare the lung deposition between bi-level and CPAP, between SB and CPAP, and between SB and bi-level. Each subject was his or her own control. Statistical analysis was performed using statistics software (SPSS 16.0, SPSS, Chicago, Illinois).

\section{Results}

All 13 subjects were able to perform measurements without problems. The clinical status of all subjects remained stable during inhalation. Table 1 shows the baseline data of subjects. All volunteers had normal spirometric values. Figure 2 shows an example of a lung scan obtained at the end of the inhalation (Subject 5), and the ROIs were defined on LL, RL, and trachea as shown in Figure 3.

The three techniques showed comparable lung deposition (Table 2). Analysis of radioaerosol deposition in the lungs showed a mean count at RL of $108.7 \pm 40$ with CPAP, $111.5 \pm 15$ with bi-level, and $196.6 \pm 167$ with SB. At LL, the finding values were $92.7 \pm 15$ with CPAP, $98.4 \pm 14$ with bi-level, and $225.0 \pm 293$ with SB. The trachea deposition was also similar: $29.8 \pm 25$ with CPAP, $28.3 \pm 19$ with bi-level, and $39.8 \pm 26$ with SB. Table 2 shows no differences in radioaerosol deposition when the LCR and its comparison with mouth and stomach were evaluated. Table 3 shows that the LCR was similar in all comparisons and that there was greater radioaerosol deposition in the stomach ([RL + LL]/stomach ratio) when the bi-level ventilatory strategy was compared with CPAP $(P=.03)$.

\section{Discussion}

There was no difference in lung regional deposition of radioaerosol delivered via nebulization to healthy individuals during SB, bi-level, and CPAP. Previous studies compared bi-level with $\mathrm{SB}^{8,11,20}$ and CPAP with $\mathrm{SB},{ }^{12}$ but this is the first study that compares the three ventilatory methods with each subject being his or her own control.

A small number of papers have been published about the treatment of patients who need NIV and bronchodilators, and some authors demonstrated that the delivery of aerosol was enhanced by intermittent positive-pressure respiration, ${ }^{18}$ whereas other investigators could not. ${ }^{20}$ França et al ${ }^{11}$ studied the pulmonary radioaerosol deposition during jet nebulization in 13 healthy volunteers and demonstrated a decrease in deposition during bi-level ventilation compared with SB nebulization. This study has an important standardization bias because the absolute count was used in scintigraphy. We believe that the use of a ratio between lung and trachea deposition is more reliable because there is no influence of small variations on radioisotope amount.

Dolovich et $\mathrm{al}^{20}$ studied the distribution of ${ }^{99 \mathrm{~m}} \mathrm{TC}$ pertechnetate in a group of stable COPD patients. They found that the positive pressure implied a rapid initial flow during inspiration with a subsequent increased impact of aerosol against tubing, mouth, and proximal airway and overall reduced deposition in the distal bronchi. We also evaluated the deposition of aerosol in the trachea, mouth, and stomach, and the bi-level strategy increased the deposition of radioaerosol in the stomach (based on the $[R L+L L] /$ stomach ratio) compared with CPAP. However, we believe that this difference is not clinically important because there was no difference between groups (CPAP, bi-level, or SB) when the ratio of deposition in RL and LL versus trachea was compared.

Some authors evaluated the lung drug deposition. Pollack et $\mathrm{al}^{8}$ proved a significant increase in peak expiratory flow with bi-level ventilation versus SB during the administration of $\beta$-agonist aerosol in wheezing patients in the emergency department. Whether aerosol particles were penetrating more deeply with bi-level ventilatory support could not be determined. In the absence of data on drug deposition, they were unable to determine whether the effect was due to NIV itself or to a synergistic action of NIV and $\beta$-adrenergic drug delivery. According to the results of our study, we could assume that there was no difference in aerosol deposition.

Parkes and Bersten ${ }^{12}$ evaluated how CPAP delivered via face mask at a flow of $50 \mathrm{~L} / \mathrm{min}$ and at a pressure of $10 \mathrm{~cm} \mathrm{H}_{2} \mathrm{O}$ could influence aerosol kinetics and bronchodilator efficacy in a group of stable asthmatic subjects. They found that in the CPAP-treated group, the availability of aerosolized drug was significantly reduced com- 
Nebulization During SB, CPAP, And Bi-Level

Table 1. Age, Body Mass Index (BMI), Maximum Expiratory Pressure $\left(\mathrm{P}_{\text {Emax }}\right)$, Maximum Inspiratory Pressure $\left(\mathrm{P}_{\text {Imax }}\right), \mathrm{FVC}, \mathrm{FEV} \mathrm{V}_{1}$, and Peak Expiratory Flow (PEF) for the Group of Subjects

\begin{tabular}{|c|c|c|c|c|c|c|c|c|c|c|}
\hline Subject & Age (y) & BMI $\left(\mathrm{kg} / \mathrm{m}^{2}\right)$ & $\mathrm{P}_{\mathrm{Emax}}\left(\mathrm{cm} \mathrm{H} \mathrm{H}_{2} \mathrm{O}\right)$ & $\mathrm{P}_{\mathrm{Imax}}\left(\mathrm{cm} \mathrm{H} \mathrm{H}_{2} \mathrm{O}\right)$ & FVC (L) & FVC $(\%)$ & $\mathrm{FEV}_{1}(\mathrm{~L})$ & $\mathrm{FEV}_{1}(\%)$ & $\mathrm{FEV}_{1} / \mathrm{FVC}(\%)$ & PEF (L/min) \\
\hline 1 & 27 & 21.3 & 85 & 80 & 3.54 & 87.4 & 2.88 & 83.4 & 82 & 400 \\
\hline 2 & 34 & 23.8 & 150 & 125 & 5.2 & 107.8 & 4.62 & 114.9 & 88 & 820 \\
\hline 3 & 27 & 21.4 & 150 & 125 & 4.2 & 92.3 & 3.52 & 90.2 & 84 & 660 \\
\hline 4 & 30 & 25.3 & 145 & 150 & 4.87 & 97.9 & 4.16 & 100 & 85 & 700 \\
\hline 5 & 39 & 29 & 150 & 130 & 4.11 & 73.6 & 3.74 & 99 & 90 & 630 \\
\hline 6 & 26 & 19.8 & 110 & 100 & 5.03 & 89 & 4.25 & 91 & 83 & 600 \\
\hline 7 & 32 & 21 & 90 & 100 & 4.2 & 120 & 3.8 & 120 & 90 & 850 \\
\hline 8 & 30 & 23.5 & 150 & 120 & 5.6 & 98.4 & 4.86 & 104.5 & 86 & 730 \\
\hline 9 & 34 & 24.9 & 110 & 80 & 4.99 & 110.3 & 3.83 & 100.5 & 76 & 900 \\
\hline 10 & 30 & 20.5 & 100 & 90 & 5.4 & 92.7 & 4.44 & 93.9 & 82 & 595 \\
\hline 11 & 30 & 22.8 & 120 & 110 & 4.99 & 100.4 & 4.25 & 104.1 & 85 & 700 \\
\hline 12 & 39 & 23.3 & 150 & 150 & 5.91 & 105.1 & 4.59 & 101.5 & 78 & 800 \\
\hline 13 & 31 & 25.2 & 140 & 140 & 4.87 & 95.8 & 4 & 96.3 & 82 & 700 \\
\hline Mean & 31 & 23.3 & 126 & 115 & 4.83 & 97.75 & 4.07 & 100.56 & 83 & 698 \\
\hline SD & 4 & 2.9 & 25 & 24 & 0.66 & 11.69 & 0.52 & 10.04 & 4 & 130 \\
\hline
\end{tabular}

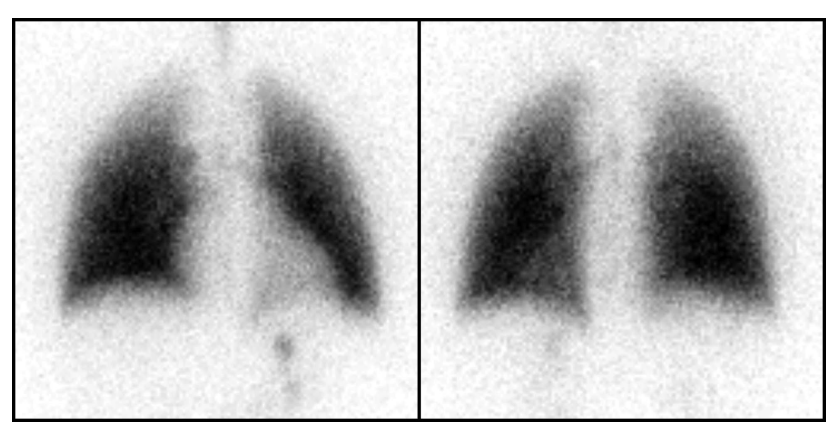

Fig. 2. Scintigraphy taken at the end of inhalation. Left: Anterior projection. Right: Posterior projection.

pared with that in the same patients inhaling bronchodilators through the same mask without CPAP. Nevertheless, the bronchodilator response was identical in the two groups as far as the dose-response curve and the improved forced expired volume were concerned, and the authors concluded that nebulized $\beta$-agonists were effectively administered by CPAP. Our study included healthy volunteers with normal lung function, making it impossible to evaluate the improvement of peak expiratory flow. Despite the equal distribution of radioaerosol suggesting the same clinical response, clinical studies in subjects with increased bronchial reactivity are needed to confirm this hypothesis.

Recently, Galindo-Filho et al ${ }^{19}$ studied 21 adults with moderate-to-severe asthma attacks who were randomized to a control group (nebulization, $n=11$ ) or experimental group (NIV + nebulization, $n=10$ ). All patients inhaled bronchodilators for $9 \mathrm{~min}$, and particles were then counted with a gamma camera to analyze ROIs and pulmonary clearance at $0,15,30,45$, and $60 \mathrm{~min}$. The authors concluded that coupling nebulization with NIV during asthma

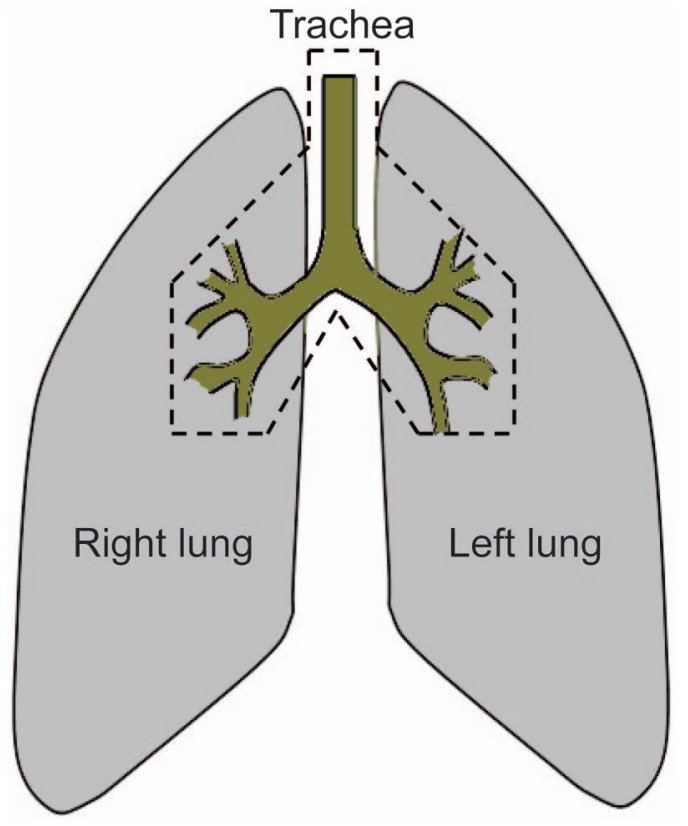

Fig. 3. Areas for radiation counting.

exacerbation did not improve pulmonary radioaerosol deposition but did improve pulmonary function in patients.

In addition, there are few studies that have evaluated delivery via MDI in patients on NIV. Nava et $\mathrm{al}^{13}$ compared the bronchodilator response of salbutamol administered via MDI with a placebo in a group of stable COPD patients during NIV and SB and found that salbutamol was equally effective whatever the mode of ventilation. Our study evaluated the distribution of radioisotopes delivered via nebulization and is not valid for MDI.

It is known that multiple factors can influence the efficiency of aerosol delivery during NIV, including the type 
Nebulization During SB, CPAP, AND Bi-Level

Table 2. Lung Calculated Ratio and Ratio Between Lung and Stomach or Mouth and All Values Using the Friedman Test (Repeated Measures)

\begin{tabular}{|c|c|c|c|c|}
\hline & \multicolumn{3}{|c|}{ Median (Minimum-Maximum) } & \multirow{2}{*}{$P^{*}$} \\
\hline & SB & Bi-Level & CPAP & \\
\hline LCR & $11.0(3.9-35.9)$ & $9.8(2.4-19.4)$ & $6.0(1.9-12.2)$ & .6 \\
\hline$(\mathrm{LL}+\mathrm{RL}) /$ stomach & $14.7(2.8-258)$ & $4.9(0.8-11.3)$ & $16.6(2.7-267)$ & .6 \\
\hline$(\mathrm{LL}+\mathrm{RL}) /$ mouth & $0.9(0.4-2.3)$ & $1.3(0.7-5.0)$ & $1.0(0.4-10.1)$ & .6 \\
\hline$(\mathrm{LL}+\mathrm{RL}) /($ trachea + stomach + mouth $)$ & $0.6(0.4-2.0)$ & $0.8(0.5-2.1)$ & $0.6(0.4-1.9)$ & .6 \\
\hline \multicolumn{5}{|c|}{$\begin{array}{l}\text { * Friedman test } \\
\text { SB = spontaneous breathing } \\
\text { Bi-level = bi-level positive-pressure ventilation } \\
\text { LCR = lung calculated ratio ([right lung + left lung]/trachea) } \\
\text { LL = left lung } \\
\text { RL = right lung }\end{array}$} \\
\hline
\end{tabular}

Table 3. Lung Calculated Ratio and Ratio Between Lung and Stomach or Mouth and All Values Using the Wilcoxon Rank-Sum Test (Paired Samples)

\begin{tabular}{lccc}
\hline \hline & \multicolumn{3}{c}{$P^{*}$} \\
\cline { 2 - 4 } & $\begin{array}{c}\text { SB vs } \\
\text { Bi-Level }\end{array}$ & $\begin{array}{c}\text { SB vs } \\
\text { CPAP }\end{array}$ & $\begin{array}{c}\text { Bi-Level vs } \\
\text { CPAP }\end{array}$ \\
\hline LCR & .17 & .26 & .4 \\
$(\mathrm{LL}+\mathrm{RL}) /$ stomach & .06 & .89 & .03 \\
$(\mathrm{LL}+\mathrm{RL}) /$ mouth & .09 & .57 & .33 \\
$(\mathrm{LL}+\mathrm{RL}) /($ trachea + & .86 & .89 & .48 \\
$\quad$ stomach + mouth) & & & \\
& & & \\
$*$ *Wilcoxon rank-sum test & & & \\
SB $=$ spontaneous breathing & & & \\
Bi-level = bi-level positive-pressure ventilation \\
LCR = lung calculated ratio ([right lung + left lung]/trachea) \\
LL = left lung \\
RL $=$ right lung \\
\hline
\end{tabular}

of ventilator, mode of ventilator, ventilator circuit, type of interface, placement of nebulizer in the circuit, drug-related factors, breathing parameters, and patient-related factors. ${ }^{7,21}$ The results of our study were not influenced by other parameters because the only variable that changed was the ventilation mode. High inspiratory flows employed during NIV increase turbulence, and the associated high inertial forces cause greater particle impact on central airways. ${ }^{22}$ However, this result was not observed in our study. The relationship between the central and peripheral distribution was equal in the three ventilatory modes.

In contrast, application of positive pressure reduces aerosol particle size, increases tidal volume, and reduces breathing frequency, all of which tend to enhance aerosol delivery. ${ }^{23-26}$ Moreover, an increase in expiratory time due to a slower breathing frequency could enhance particle sedimentation and alter the pattern of drug deposition during exhalation. ${ }^{24}$

Our study has some limitations. First, the sample was small; however, because all volunteers were their own control, this limitation becomes less important. Second, we evaluated subjects with healthy lungs, and the results cannot be applied to patients with sick lungs. However, this allows us to better assess the effect of ventilation on radioaerosol distribution without the influence of structural lung disease. Because the inhalation study was a radioisotope study, masks with exhalation were not used. Therefore, the results are valid for the use of an NIV closed system, without regard to loss of contents. Moreover, conclusions about the different positions of exhalation port and mask design cannot be drawn.

Delivery of aerosols to patients receiving NIV is complex. We believe that our study has important clinical and research implications, considering that the use of aerosol during NIV could be effective in the delivery of drugs into lower airways. This knowledge is necessary to safely study the use of aerosol via NIV in patients with sick lungs. Further studies are needed to assess the efficacy of aerosol delivered via NIV in these patients.

\section{REFERENCES}

1. Soo Hoo GW, Hakimian N, Santiago SM. Hypercapnic respiratory failure in COPD patients: response to therapy. Chest 2000;117(1): 169-177.

2. Vestbo J, Hurd SS, Agusti AG, Jones PW, Vogelmeier C, Anzueto A, et al. Global strategy for diagnosis, management, and prevention of chronic obstructive pulmonary disease-GOLD Executive Summary. Am J Respir Crit Care Med 2013;187(4):347-365.

3. Lightowler JV, Wedzicha JA, Elliott MW, Ram FSF. Non-invasive positive pressure ventilation to treat respiratory failure resulting from exacerbations of chronic obstructive pulmonary disease: Cochrane systematic review and meta-analysis. BMJ 2003;326(3):185-189.

4. Hill NS. Noninvasive ventilation for chronic obstructive pulmonary disease. Respir Care 2004;49(1):72-87.

5. Calverley PM. Chronic obstructive pulmonary disease. In: Fink MP, Abrahan E, Vincent JL, Kochanek PM, editors. Textbook of Critical Care, 5th edition. Philadelphia: Elsevier Sauders; 2005:599-608.

6. Quon BS, Gan WQ, Sin DD. Contemporary management of acute exacerbations of COPD: a systematic review and meta-analysis. Chest 2008;133(3):756-766. 
7. Dhand R. Aerosol therapy in patients receiving noninvasive positive pressure ventilation. J Aerosol Med Pulm Drug Deliv 2012;25(2): 63-78.

8. Pollack CV Jr, Fleisch KB, Dowsey K. Treatment of acute bronchospasm with beta-adrenergic agonist aerosols delivered by a nasal bilevel positive airway pressure circuit. Ann Emerg Med 1995;26(5): 552-557.

9. Chatmongkolchart S, Schettino GP, Dillman C, Kacmarek RM, Hess DR. In vitro evaluation of aerosol bronchodilator delivery during noninvasive positive pressure ventilation: effect of ventilator settings and nebulizer position. Crit Care Med 2002;30(11):2515-2519.

10. Dhand R. Inhalation therapy in invasive and noninvasive mechanical ventilation. Curr Opin Crit Care 2007;13(1):27-38

11. França EET, Dornelas de Andrade AF, Cabrala G, Almeida-Filho P, Silva KC, Galindo-Filho VC, et al. Nebulization associated with bi-level noninvasive ventilation: analysis of pulmonary radioaerosol deposition. Respir Med 2006;100:721-728.

12. Parkes SN, Bersten AD. Aerosol kinetics and bronchodilator efficacy during continuous positive airway pressure delivered by face mask. Thorax 1997;52(2):171-175.

13. Nava S, Karakurt S, Rampulla C, Braschi A, Fanfulla F. Salbutamol delivery during non-invasive mechanical ventilation in patients with chronic obstructive pulmonary disease: a randomized controlled study. Intensive Care Med 2001;27(10):1627-1635.

14. Schettino GPP, Chatmongkolchart S, Hess DR, Kacmarek RM. Position of exhalation port and mask design affect $\mathrm{CO}_{2}$ rebreathing during noninvasive positive pressure ventilation. Crit Care Med 2003; 31(8):2178-2182.

15. Thomas SHL, Langford JA, George RJD, Geddes DM. Aerosol deposition in the human lung: effect of high-frequency oscillation on the deposition characteristics of an inhaled nebulized aerosol. Clin Sci 1988;75(5):535-542.

16. Branconnier MP, Hess DR. Albuterol delivery during noninvasive ventilation. Respir Care 2005;50(12):1649-1653.
17. Fauroux B, Itti E, Pigeot J, Isabey D, Meignan M, Ferry G, et al. Optimization of aerosol deposition by pressure support in children with cystic fibrosis. Am J Respir Crit Care Med 2000;162(6):22652271.

18. Shenfield GM, Evans ME, Walker SR, Paterson JW. The fate of nebulized salbutamol administered by intermittent positive pressure respiration to asthmatic patients. Am Rev Respir Dis 1973;108(3): 501-505.

19. Galindo-Filho VC, Brandão DC, Ferreira RCS, Menezes MJ, Almeida-Filho P, Parreira VF, et al. Noninvasive ventilation coupled with nebulization during asthma crises: a randomized controlled trial. Respir Care 2013;58(2):241-249.

20. Dolovich MB, Killian D, Wolff RK, Obminski G, Newhouse MT. Pulmonary aerosol deposition in chronic bronchitis: intermittent positive pressure breathing versus quiet breathing. Am Rev Respir Dis 1977;115(3):397-402.

21. Dhand R, Guntur VP. How best to deliver aerosol medications to mechanically ventilated patients. Clin Chest Med 2008;29(2):277296.

22. Dolovich MA. Influence of inspiratory flow rate, particle size, and airway caliber on aerolized drug delivery to the lung. Respir Care 2000;45(6):597-608.

23. Calvert LD, Jackson JM, White JA, Barry PW, Kinnear WJ, O'Callaghan C. Enhanced delivery of nebulised salbutamol during non-invasive ventilation. J Pharm Pharmacol 2006;58(11):1553-1557.

24. Smaldone GC. Assessing new technologies: patient-device interactions and deposition. Respir Care 2005;50(9):1151-1160.

25. Guerin C, Fassier T, Bayle F, Lemasson S, Richard JC. Inhaled bronchodilator administration during mechanical ventilation: how to optimize it, and for which clinical benefit? J Aerosol Med Pulm Drug Deliv 2008;21(1):85-96.

26. Kallet RH. Adjunct therapies during mechanical ventilation: airway clearance techniques, therapeutic aerosols, and gases. Respir Care 2013;58(6):1053-1073.

This article is approved for Continuing Respiratory Care Education credit. For information and to obtain your CRCE

(free to AARC members) visit

www.rcjournal.com

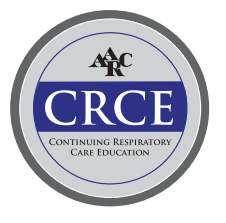

